\title{
Comparative Studies of the Adsorption of Direct Dye on Activated Carbon and Conducting Polymer Composite
}

\author{
J. RAFFIEA BASERI*1 ${ }^{1}$, P. N. PALANISAMY ${ }^{2}$ and P. SIVAKUMAR ${ }^{3}$ \\ ${ }^{1}$ Department of Chemistry, Al-Ameen Engineering College, Erode, Tamilnadu-638 104, \\ India \\ ${ }^{2}$ Department of Chemistry, Kongu Engineering College, Perundurai, Erode, Tamilnadu- 638 \\ 052, India \\ ${ }^{3}$ Department of Chemistry, Arignar Anna Government Arts College, Namakkal, Tamilnadu- \\ 637002 , India \\ raffiea2010@gmail.com
}

Received 9-Nov-2011; Accepted 15-Jan-2012

\begin{abstract}
This study analyses the feasibility of removing Direct Blue 71 from aqueous solution by different adsorbents such as activated carbon (TPAC) and Poly pyrrole polymer composite (PPC) prepared from Thevetia Peruviana. Batch mode adsorption was performed to investigate the adsorption capacities of these adsorbents by varying initial dye concentration, temperature, agitation time and $\mathrm{pH}$. The performance of TPAC was compared with PPC. Among the adsorbents, PPC had more adsorption capacity $(88.24 \%)$ than TPAC $(58.82 \%)$ at an initial concentration of $50 \mathrm{mg} / \mathrm{L}$ and at $30^{\circ} \mathrm{C}$. The experimental data best fitted with pseudo second order kinetic model. The adsorption data fitted well for Langmuir adsorption isotherm. Thermodynamic parameters for the adsorbents were also evaluated. The carbon embedded in conducting polymers matrix show better adsorptive properties than activated carbon.
\end{abstract}

Key words: Adsorption, Langmuir isotherm, kinetics, conducting polymer, direct blue 71 .

\section{Introduction}

Textile industries rank first in the usage of dyes when compared to other industries like food, paper, cosmetics and carpet industries ${ }^{1}$. Effluents discharged from dyeing industries are highly colored and toxic. Decolorization of textile effluents using the conventional technologies is not effective because of their limitations ${ }^{2}$. Direct dyes possess good affinity to cellulosic fibers and they are widely used due to their low cost, excellent colour range and good light fastness ${ }^{3}$. Many of them are highly toxic and carcinogenic ${ }^{4}$. Many physical and 
chemical methods including adsorption, coagulation, precipitation and filtration have been used to remove harmful dyes from colored waste water. Adsorption is the most economical and effective method for removal of dyes.

Though commercial activated carbon is an ideal adsorbent for the removal of dyes from effluent, it is uneconomical due to its high production cost and regeneration costs. Many researchers have proved several low cost materials such as pear millet husk carbon ${ }^{5}$, aspergillus niger ${ }^{6}$, rice husk, banana pith, cotton waste, kaoline ${ }^{7}$, coir pith $^{8}$, guava seeds ${ }^{9}$, neem saw dust ${ }^{10}$, clay ${ }^{11}$ and mango seed kernel ${ }^{12}$ as suitable adsorbents for the removal of dyes. Conducting polymers such as Poly pyrrole coated on saw dust are recently used as novel adsorbents due to their electrical conductivity and electro negativity ${ }^{13}$. Also Polymers have an advantages of less sludge generation and effective in both batch and column mode systems.

In this study, Poly pyrrole polymer composite was chemically synthesized on the saw dust of Thevetia peruviana. Also activated carbon was prepared by carbonization of Thevetia peruviana wood followed by chemical impregnation with $\mathrm{H}_{3} \mathrm{PO}_{4}$. The comparative study of the conducting polymer composite and activated carbon for the adsorption of direct blue71 from textile waste water was conducted by batch mode adsorption tests.

\section{Experimental}

\section{Preparation of Activated Carbon (TPAC)}

Thevetia Peruviana wood was cut into pieces of $2 \mathrm{~cm}$ to $3 \mathrm{~cm}$ size, dried in sunlight for 10 days. The dried material was soaked in a boiling solution of $40 \% \mathrm{H}_{3} \mathrm{PO}_{4}$ for one hour and kept at room temperature for 24 hours. After 24 hour, the wood material was separated, air dried and carbonized in muffle furnace at $400^{\circ} \mathrm{C}$. The carbonized material was powdered and activated in a muffle furnace at $800^{\circ} \mathrm{C}$ for a period of 10 minutes. Then the material was washed with plenty of water to remove residual acid, dried, sieved to a desired particle size and stored in a tight lid container for further adsorption studies. The characteristics of the activated carbon are analyzed as per the standard procedures ${ }^{14,15}$ and given in Table 1 . The surface morphology of TPAC visualized via Scanning Electron Microscope (SEM), (Make Jeol, Model 6390LA) at 500X magnification.

\section{Preparation of PolyPyrrole Polymer Composite}

Thevetia peruviana Sawdust was washed with distilled water in order to remove any dust or impurities and finally dried at $60^{\circ} \mathrm{C}$ for 2 hours in an air oven. In order to achieve uniform coating, the sawdust sieved into a particle size of 180 to $300 \mu$ before coating. The polymerization was done on sawdust by soaking in the monomer solutions $(0.20 \mathrm{M})$. The oxidant $\left(0.50 \mathrm{M} \mathrm{FeCl}_{3}\right)$ slowly added with the mixture at room temperature for 2 hours. The polymer coated sawdust was filtered, washed with distilled water, dried at $60^{\circ} \mathrm{C}$ (in an oven) and sieved before use ${ }^{16}$. The coating percentage of each polymer onto saw dust determined by weight difference of the dried sawdust before and after coating and it was nearly $5 \%{ }^{17}$.

\section{Preparation of Direct Dye Solution}

The dye used in this study was Direct Blue 71 having molecular formula $\mathrm{C}_{40} \mathrm{H}_{23} \mathrm{~N}_{7} \mathrm{Na}_{4} \mathrm{O}_{13} \mathrm{~S}_{4}$ (Mol.Wt:1029.88) with CI No. 34140. The molecular structure of DB71 is given in Figure 1.The stock solution of $1000 \mathrm{mg} / \mathrm{L}$ of the DB71 dye was prepared by dissolving $1000 \mathrm{mg}$ of the dye in 1 litre double distilled water. The experimental solutions were obtained by diluting the dye stock solutions in accurate proportions to different initial concentrations. 


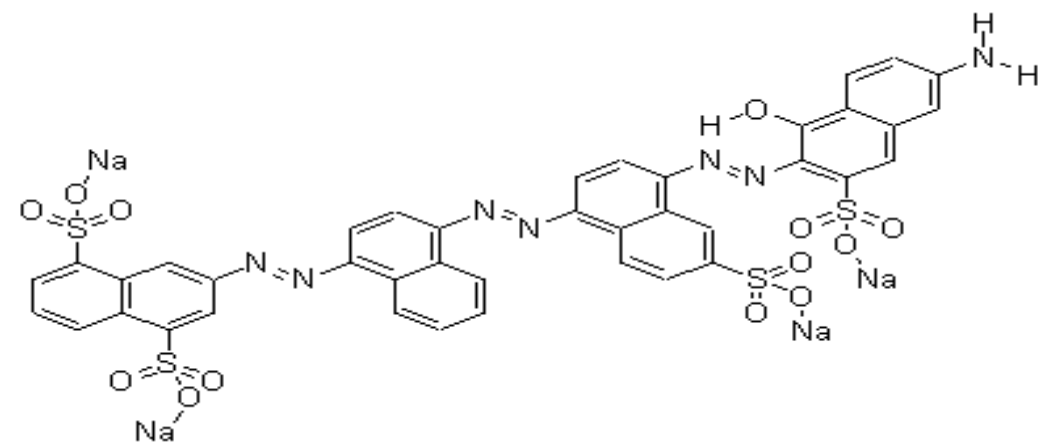

Figure 1. Molecular structure of Direct Blue 71.

\section{Batch Mode Adsorption Experiments}

The adsorption experiments were carried out by agitating $100 \mathrm{mg}$ adsorbent with $200 \mathrm{~mL}$ of dye solutions of 25 to $100 \mathrm{mg} / \mathrm{L}$ concentration at $150 \mathrm{rpm}$ on an Orbital shaker (REMI make). The mixture was withdrawn at specified intervals, centrifuged using electrical centrifuge (Universal make) at 5000rpm for 20 minutes and unadsorbed supernatant liquid was analyzed for the residual dye concentration using Elico make UV Spectrophotometer (CI 73) at $\lambda \max$ of $587 \mathrm{~nm}$. The effect of $\mathrm{pH}$ was studied by using dilute $\mathrm{HCl}$ and $\mathrm{NaOH}$ solutions. The effect of temperature was studied at four different temperatures $(30,35,40$ and $45^{\circ} \mathrm{C}$ ). All experiments were carried out in duplicate and the mean values are reported, where the maximum deviation was within $4 \%$. The effects of each parameter (initial dye concentration, $\mathrm{pH}$, agitation time) were evaluated in an experiment by varying that parameter, while other parameters are maintained as constant. The amount of dye on PAC adsorbent was calculated from the following equation

$$
q_{t}=\frac{\left(C_{0}-C_{e}\right)}{M} \mathrm{~V},
$$

where, $\mathrm{q}_{\mathrm{t}}(\mathrm{mg} / \mathrm{g})$ is the amount of dye adsorbed at time $\mathrm{t}, \mathrm{C}_{0}$ and $\mathrm{C}_{\mathrm{e}}(\mathrm{mg} / \mathrm{L})$ are the concentrations of dye at initial and equilibrium respectively. $\mathrm{V}(\mathrm{L})$ is the volume of the solution and $\mathrm{M}(\mathrm{g})$ is the mass of dry adsorbent used.

\section{Desorption Studies}

The regeneration of the adsorbent may make the treatment process economical. The supernatant was separated after centrifugation and the adsorbent was separated and allowed to agitate with $100 \mathrm{~mL}$ of distilled water at different $\mathrm{pH}(2-11)$ above the equilibrium time of adsorption. The desorbed dye solution was estimated as given in the adsorption studies ${ }^{18}$.

\section{Results and Discussion}

\section{Characterization Studies}

Characteristics of carbon prepared from Thevetia Peruviana are presented in Table 1. Examination of SEM micrograph (Figure 2a) of the TPAC showed rough areas on the surface of the carbon. SEM micrographs of PPC (Figure $2 \mathrm{~b}$ ) showed the formation of the polymer matrix on the surface of the sawdust. 
Table 1. Physico - Chemical characteristics of TPAC and PPC.

\begin{tabular}{|l|c|c|c|}
\hline S.No & Properties & TPAC & PPC \\
\hline 1 & $\mathrm{pH}$ & 6.68 & 7.25 \\
\hline 2 & Moisture Content, $\%$ & 12.2 & 13.7 \\
\hline 3 & Conductivity, $\mathrm{mS} \mathrm{cm}^{-2}$ & 0.156 & 6.33 \\
\hline 4 & Methylene Blue Number $\mathrm{mg} / \mathrm{g}$ & 420 & 53 \\
\hline 5 & Iodine Number, $\mathrm{mg} / \mathrm{g}$ & 825 & 95 \\
\hline 6 & Volatile matter, $\%$ & 23.2 & 52.9 \\
\hline
\end{tabular}

\section{Effect of Agitation Time and Initial Dye Concentration}

In order to determine the rate of adsorption, experiments were conducted at different initial dye concentrations ranging from 25 to $100 \mathrm{mg} / \mathrm{L}$ at $30^{\circ} \mathrm{C}$. The variation in the percentage removal of DB71 with contact time at an initial dye concentration of $50 \mathrm{mg} / \mathrm{L}$ by various adsorbents TPAC and PPC are shown in Figure.3. It was observed that the maximum amount of dye adsorbed within the contact time of 30 minutes and it reached equilibrium at 50 minutes for TPAC and 90 minutes for PPC. After that no significant change was observed in the extent of adsorption. The percentage of dye removal decreased from 62.96 $\%$ to $53.85 \%$ for TPAC and $96.30 \%$ to $83.08 \%$ for PPC while increasing the initial dye concentrations from 25 to $100 \mathrm{mg} / \mathrm{L}$. If initial dye concentration is increased, there is an increased competition for the active adsorption sites and the adsorption process will slow down.



(2a)

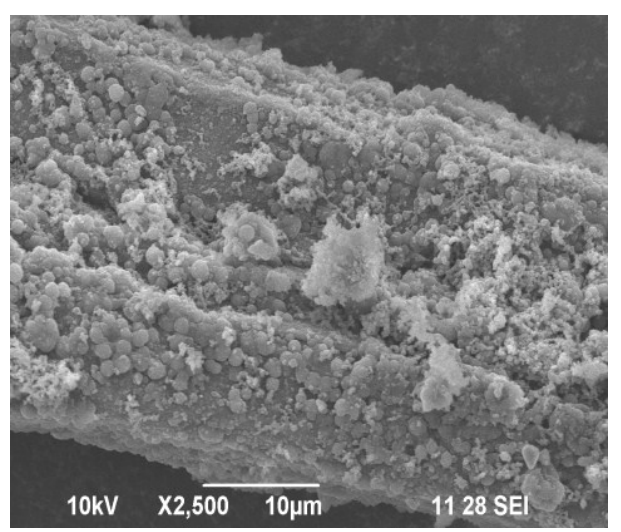

(2b)

Figure 2. Scanning Electron Micrographs of TPAC and PPC.

The adsorption curves are single, smooth and continuous till the saturation of dye on the carbon surface. The adsorption capacity at equilibrium increased from $31.48 \mathrm{mg} / \mathrm{g}$ to $107.69 \mathrm{mg} / \mathrm{g}$ for TPAC and $48.15 \mathrm{mg} / \mathrm{g}$ to $166.10 \mathrm{mg} / \mathrm{g}$ for PPC with an increase in the initial concentrations from 25 to $100 \mathrm{mg} / \mathrm{L}$. This is due to the increase in availability of the dye molecules near adsorbent. Similar behaviors were reported for the adsorptive removal of Direct Blue 67 by low cost rice husk waste ${ }^{19}$ and the adsorption of Direct Yellow 86 and Direct Red 224 on carbon nanotubes ${ }^{20}$. 
The amount of DB71 removal by the TPAC is less than that of PPC. This may be due to the heterogeneity obtained by the presence of functional groups on the surface of the polymer composites ${ }^{16}$. The pores on the surface of activated carbon may not be fully occupied by dye molecules where as the dye molecules may occupy more sites on the polymer composites due to the orderly arrangement of polymer matrix. From the literature ${ }^{13}$, it was suggested that the rate of dye removal was high due to the ion exchange mechanism between the oppositely charged functionalities originating from monomer (or oxidant solutions during their synthesis )and the anionic dye molecules.

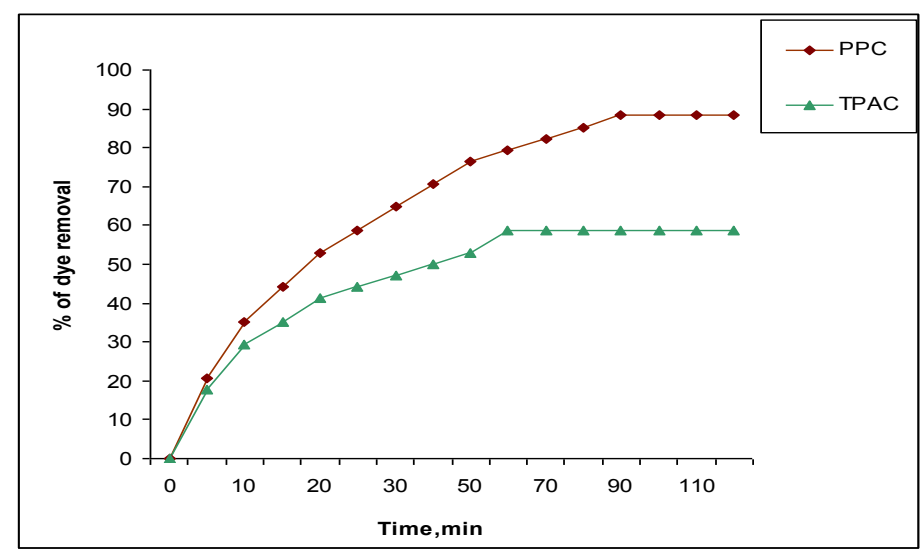

Figure 3. Effect of agitation time on the percentage removal of DB 71 dye on TPAC and $\mathrm{PPC}$ at $30^{\circ} \mathrm{C}$ (adsorbent dosage, $100 \mathrm{mg}$; $\mathrm{pH}, 4.3$; initial dye concentration, $50 \mathrm{mg} / \mathrm{L}$ ).

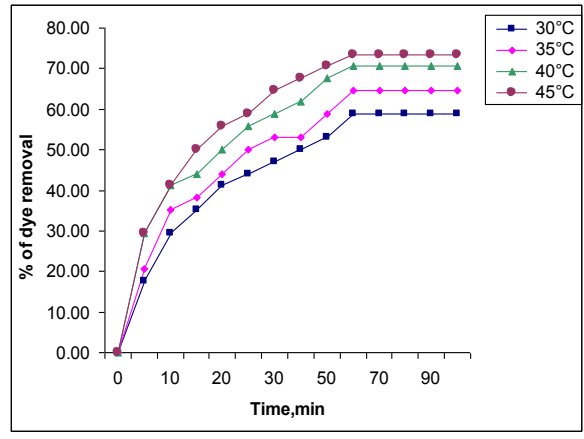

4(a)

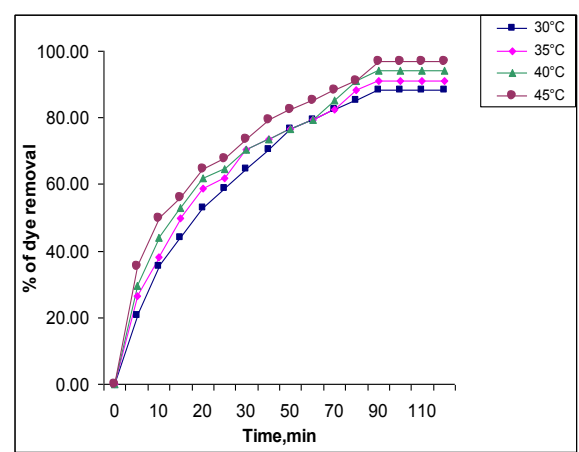

4(b)

Figure 4. Effect of temperature on the adsorption of DB 71 dye on to TPAC and PPC at initial concentration of $50 \mathrm{mg} / \mathrm{L}$ (adsorbent dosage, 100mg; $\mathrm{pH}, 4.3$ ).

\section{Effect of Temperature}

The experiments were carried out at four different temperatures $\left(30,35,40\right.$ and $\left.45^{\circ} \mathrm{C}\right)$ to observe the effect of temperature on the adsorption of DB71 by TPAC and PPC respectively and the results are shown in Figure $4 \mathrm{a} \& 4 \mathrm{~b}$. The percentage removal of DB71 increased from $58.82 \%$ to $73.53 \%$ on TPAC and $88.24 \%$ to $97.06 \%$ on PPC respectively on 
increasing the temperature. This indicates that the sorption of direct dye on given activated carbon and conducting polymer composite of Thevetia Peruviana is an endothermic process.

\section{Effect of $p H$}

The percentage of dye adsorption by activated carbon as well as for polymer composites was maximum at $\mathrm{pH} 2$ and decreased on increasing the $\mathrm{pH}$. This is due to high electrostatic attraction between the positively charged (high concentrations of $\mathrm{H}^{+}$) surface of the adsorbents and anionic dye $\mathrm{e}^{21}$. When the $\mathrm{pH}$ is increased; the electrostatic repulsion increases and the adsorption rate get decreased.

\section{Kinetics Studies}

In this study, the adsorption DB71 onto different adsorbents was analyzed using pseudo-first order and pseudo-second order kinetic models. Pseudo first - order kinetic model assumes that the rate of change of solute uptake with time is directly proportional to difference in solution concentration and the amount of solid uptake. The pseudo-first order rate equation proposed Lagergren ${ }^{22}$ is

$$
\frac{d q_{t}}{d t}=k_{1}\left(q_{e}-q_{t}\right)
$$

where, $\mathrm{q}_{\mathrm{t}}$ and $\mathrm{q}_{\mathrm{e}}$ are the amount of dye adsorbed $(\mathrm{mg} / \mathrm{g}$ ) at time $\mathrm{t}(\mathrm{min})$ and at equilibrium, and $\mathrm{k}_{1}$ is the pseudo-first order rate constant $\left(\mathrm{min}^{-1}\right)$. The integrated linear form of pseudofirst order equation is

$$
\log \left(q_{e}-q_{t}\right)=\log q_{e}-\frac{k_{1}}{2.303} t
$$

The plot of $\log \left(\mathrm{q}_{\mathrm{e}}-\mathrm{q}_{\mathrm{t}}\right)$ versus $\mathrm{t}$ should give a straight line with slope of $-\mathrm{k}_{1} / 2.303$ and intercept $\log \mathrm{q}_{\mathrm{e}}$. Calculated values of $\mathrm{k}_{1}$ and $\mathrm{q}_{\mathrm{e}}$ are summarized for the adsorption of DB71 on TPAC and PPC (figure not shown) at different initial dye concentrations and different temperatures in Table $2 \mathrm{a} \& 2 \mathrm{~b}$. Similar results were observed for the adsorption of Congo red by chitosan hydrogel beads impregnated with cetyl trimethyl ammonium bromide ${ }^{23}$. The pseudo first-order kinetic model of Lagergren does not fit well with the experimental data over the whole range of initial concentrations studied.

The pseudo-second order kinetic equation is expressed as

$$
\frac{t}{q_{t}}=\frac{1}{k_{2} q_{e}^{2}}+\frac{t}{q_{e}},
$$

where, $k_{2}$ is the rate constant $(\mathrm{g} / \mathrm{mg} \min )$ and $q_{e}$ is the equilibrium adsorption capacity $(\mathrm{mg} / \mathrm{g})^{23}$.

The initial adsorption rate, $\mathrm{h},(\mathrm{mg} / \mathrm{g} \mathrm{min})$ is expressed as

$$
\mathrm{h}=k_{2} q_{e}^{2}
$$


Table 2(a). Kinetic parameters for the adsorption of direct dye DB 71 onto TPAC and PPC with different initial dye concentration at temperature $30^{\circ} \mathrm{C}$.

\begin{tabular}{|c|c|c|c|c|c|c|c|c|}
\hline Adsorbents & \multicolumn{4}{|c|}{ TPAC } & \multicolumn{4}{|c|}{ PPC } \\
\hline \multirow{2}{*}{ Parameter } & \multicolumn{8}{|c|}{ Initial dye concentration, $\mathrm{mg} / \mathrm{L}$} \\
\hline & 25 & 50 & 75 & 100 & 25 & 50 & 75 & 100 \\
\hline $\mathrm{q}_{\mathrm{e}} \exp .(\mathrm{mg} / \mathrm{g})$ & 31.48 & 58.82 & 84.38 & 107.69 & 48.15 & 88.24 & 131.25 & 166.15 \\
\hline \multicolumn{9}{|c|}{ Pseudo first order kinetics } \\
\hline $\mathrm{k}_{1 \mathrm{x}} 10^{-2}\left(\min ^{-1}\right)$ & 4.58 & 5.44 & 5.9 & 6.08 & 3.71 & 3.94 & 4.65 & 4.74 \\
\hline $\mathrm{q}_{\mathrm{e}} \mathrm{cal}(\mathrm{mg} / \mathrm{g})$ & 23.72 & 56.14 & 79.85 & 93.84 & 43.36 & 81.62 & 160.84 & 193.69 \\
\hline $\mathrm{r}^{2}$ & 0.9643 & 0.9540 & 0.9508 & 0.9416 & 0.9885 & 0.9929 & 0.9403 & 0.9775 \\
\hline \multicolumn{9}{|c|}{ Pseudo second order kinetics } \\
\hline $\begin{array}{l}\mathrm{k}_{2} \times 10^{-4} \\
(\mathrm{~g} / \mathrm{mg} \min )\end{array}$ & 25.15 & 10.97 & 9.41 & 9.56 & 8.88 & 4.98 & 2.57 & 1.94 \\
\hline $\mathrm{h}$ & 0.0398 & 0.0911 & 0.1063 & 0.1046 & 2.8994 & 5.4025 & 6.689 & 8.4104 \\
\hline $\mathrm{q}_{\mathrm{e}} \mathrm{cal}(\mathrm{mg} / \mathrm{g})$ & 35.71 & 68.03 & 95.24 & 119.05 & 57.14 & 104.17 & 161.29 & 208.33 \\
\hline $\mathrm{r}^{2}$ & 0.9982 & 0.9974 & 0.9979 & 0.9987 & 0.9986 & 0.9989 & 0.9972 & 0.9952 \\
\hline
\end{tabular}

Table 2(b). Kinetic parameters for the adsorption of direct dye DB 71 onto TPAC and PPC with different temperatures at initial dye concentration of $50 \mathrm{mg} / \mathrm{L}$.

\begin{tabular}{|c|c|c|c|c|c|c|c|c|}
\hline Adsorbents & \multicolumn{4}{|c|}{ TPAC } & \multicolumn{4}{|c|}{ PPC } \\
\hline \multirow{2}{*}{ Parameter } & \multicolumn{8}{|c|}{ Temperature, ${ }^{\circ} \mathrm{C}$} \\
\hline & 30 & 35 & 40 & 45 & 30 & 35 & 40 & 45 \\
\hline $\mathrm{q}_{\mathrm{e}} \exp .(\mathrm{mg} / \mathrm{g})$ & 58.82 & 64.71 & 70.59 & 73.53 & 88.24 & 91.18 & 94.12 & 97.06 \\
\hline \multicolumn{9}{|c|}{ Pseudo first order kinetics } \\
\hline $\begin{array}{l}\mathrm{k}_{1 \mathrm{x}} 10^{-2} \\
\left(\mathrm{~min}^{-1}\right)\end{array}$ & 5.44 & 5.55 & 5.73 & 5.76 & 3.94 & 3.55 & 3.43 & 3.11 \\
\hline $\mathrm{q}_{\mathrm{e}} \mathrm{cal}(\mathrm{mg} / \mathrm{g})$ & 56.14 & 61.73 & 60.63 & 57.6 & 81.62 & 75.53 & 76.54 & 69.14 \\
\hline $\mathrm{r}^{2}$ & 0.9540 & 0.9463 & 0.9648 & 0.9706 & 0.9929 & 0.9512 & 0.9292 & 0.9723 \\
\hline \multicolumn{9}{|c|}{ Pseudo second order kinetics } \\
\hline $\begin{array}{l}\mathrm{k}_{2} \times 10^{-4} \\
(\mathrm{~g} / \mathrm{mgmin})\end{array}$ & 10.97 & 10.47 & 12.89 & 14.17 & 4.98 & 5.73 & 5.83 & 6.72 \\
\hline $\mathrm{h}$ & 0.0911 & 0.0955 & 0.0776 & 0.0706 & 5.4025 & 6.3532 & 6.7431 & 7.9428 \\
\hline $\mathrm{q}_{\mathrm{e}} \mathrm{cal}(\mathrm{mg} / \mathrm{g})$ & 68.03 & 74.63 & 78.74 & 81.3 & 104.17 & 105.26 & 107.53 & 108.7 \\
\hline $\mathrm{r}^{2}$ & 0.9974 & 0.9964 & 0.9977 & 0.9986 & 0.9989 & 0.9979 & 0.9959 & 0.9975 \\
\hline
\end{tabular}

Figure 5a $\& 5$ b show the pseudo-second order plots for the adsorption of DB71 on TPAC and PPC respectively at various initial dye concentrations and $30^{\circ} \mathrm{C}$. The value of $k_{2}$ and $\mathrm{q}_{\mathrm{e}}$ determined from the intercept and slope of the plot. The rate constant, $k_{2}$ decreases with 
increase in initial dye concentration. From the results given in Table 2(a \& b), the adsorption of DB71 at different initial dye concentration and temperatures fits well to the pseudo second order kinetic model than the pseudo first order kinetic model with high correlation coefficient



5(a)

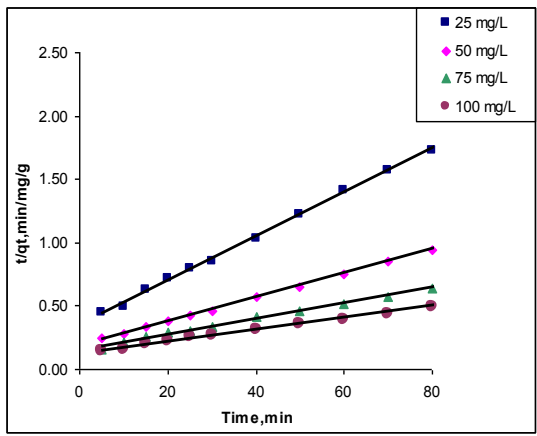

5(b)

Figure 5. Pseudo second order plots for the adsorption of DB 71 dye onto TPAC and PPC at $30^{\circ} \mathrm{C}$ (adsorbent dosage, 100mg; $\mathrm{pH}, 4.3$ ).

\section{Equilibrium Adsorption Isotherm}

Adsorption isotherm indicates the relationship between the adsorbate in the liquid phase and the adsorbate adsorbed on the surface of the adsorbent at equilibrium at constant temperatures ${ }^{24}$. The applicability of the isotherm equation is compared by judging the correlation coefficients $\left(\mathrm{r}^{2}\right)$.

The Langmuir adsorption isotherm is the best known linear model for monolayer adsorption on the homogeneous surface and most frequently utilized to determine the adsorption parameters. Langmuir model is represented by the following equation:

$$
\frac{C_{e}}{q_{e}}=\frac{1}{Q_{o} b_{L}}+\left(\frac{1}{Q_{o}}\right) C_{e},
$$

where $q_{e}$ the amount is adsorbed at equilibrium $(\mathrm{mg} / \mathrm{g}), Q_{o}$ is the monolayer adsorption capacity $(\mathrm{mg} / \mathrm{g}), C_{e}$ is the equilibrium concentration of adsorbate $(\mathrm{mg} / \mathrm{l})$ and $b_{L}$ is Langmuir constant related to energy of adsorption.

Figure $6(\mathrm{a} \& \mathrm{~b})$ show a linearized plot of $\mathrm{Ce} / \mathrm{q}_{\mathrm{e}}$ against $\mathrm{C}_{\mathrm{e}}$. Values of $\mathrm{Q}_{\mathrm{o}}$ and $\mathrm{b}_{\mathrm{L}}$ were calculated and given in Table 3. The Langmuir adsorption capacities of DB71 dye varies from $129.87 \mathrm{mg} / \mathrm{g}$ to 


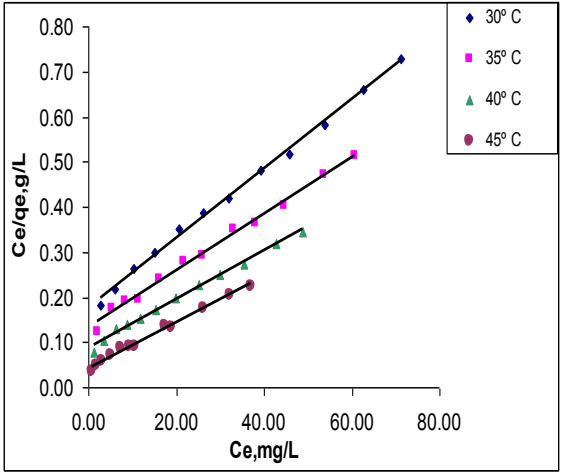

6(a)

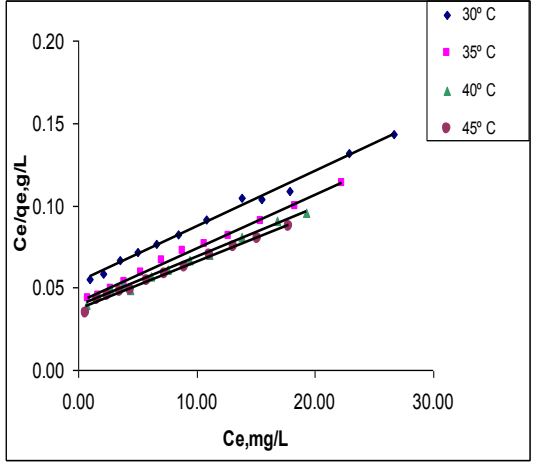

6(b)

Figure 6. Langmuir adsorption isotherm plots for the adsorption of DB 71 dye onto TPAC and PPC (adsorbent dosage, 100mg; pH, 4.3; agitation time, $120 \mathrm{~min}$ ).

$196.08 \mathrm{mg} / \mathrm{g}$ for TPAC and $294.12 \mathrm{mg} / \mathrm{g}$ to $344.83 \mathrm{mg} / \mathrm{g}$ for PPC respectively on increasing in temperature from $30^{\circ} \mathrm{C}$ to $45^{\circ} \mathrm{C}$. This indicated that the adsorption was favor at high operating temperature. Similar values were reported already for the removal of direct dye DB71 by the low cost adsorbent ${ }^{25}$. The maximum adsorption corresponds to a saturated mono layer of dye molecules on the adsorbent surface with constant energy and there is no transmission of dye molecules on the adsorbent surface occurs. Further it confirms the endothermic nature of the processes involved due to the increase in adsorption capacity with increase in temperature of the system. The experimental data fits quite well for Langmuir isotherm with the good correlation coefficient as shown in Table 3.

The separation factor $\mathrm{R}_{\mathrm{L}}$ is calculated by the following equation to confirm the favorability of the adsorption process.

$$
\mathrm{R}_{\mathrm{L}}=1 /\left(1+\mathrm{b}_{\mathrm{L}} \cdot \mathrm{C}_{0}\right),
$$

where $b_{L}$ is the Langmuir constant and $C_{0}$ is the initial concentration of dye $(\mathrm{mg} / \mathrm{L})$. The values of $\mathrm{R}_{\mathrm{L}}$ found to be between 0 and 1 indicating that the adsorption process is favorable.

The Freundlich equation is an empirical relationship describing the sorption of solutes from a liquid to a solid surface. Linear form of Freundlich equation is

$$
\log q_{e}=\log k_{f}+\frac{1}{n} \log C_{e}
$$


Table 3. Isotherm Constants for the adsorption of direct dye, DB 71 onto TPAC and PPC at various Temperatures

\begin{tabular}{|c|c|c|c|c|c|c|c|c|}
\hline Adsorbents & \multicolumn{4}{|c|}{ TPAC } & \multicolumn{4}{|c|}{ PPC } \\
\hline \multirow{2}{*}{ Parameter } & \multicolumn{8}{|c|}{ Temperature ${ }^{\circ} \mathrm{C}$} \\
\hline & 30 & 35 & 40 & 45 & 30 & 35 & 40 & 45 \\
\hline \multicolumn{9}{|c|}{ Langmuir Isotherm } \\
\hline $\mathrm{Q}_{0}(\mathrm{mg} / \mathrm{g})$ & 129.87 & 158.73 & 188.68 & 196.08 & 294.12 & 303.03 & 333.33 & 344.83 \\
\hline $\mathrm{b}_{\mathrm{L}}(\mathrm{L} / \mathrm{mg})$ & 0.0435 & 0.0475 & 0.06 & 0.1229 & 0.0637 & 0.0797 & 0.0773 & 0.0795 \\
\hline $\mathrm{r}^{2}$ & 0.9974 & 0.9935 & 0.9929 & 0.9919 & 0.9931 & 0.9969 & 0.9915 & 0.9902 \\
\hline \multicolumn{9}{|c|}{ Freundlich Isotherm } \\
\hline $\mathrm{n}$ & 1.75 & 1.69 & 1.7 & 1.87 & 1.42 & 1.43 & 1.37 & 1.38 \\
\hline $\begin{array}{l}\mathrm{k}_{\mathrm{f}} \\
\left(\mathrm{mg}^{1-1 / n} \mathrm{~L}^{1 / n} \mathrm{~g}^{-1}\right)\end{array}$ & 27.63 & 16.26 & 11.93 & 9.74 & 20.99 & 25.5 & 26.35 & 28.02 \\
\hline $\mathrm{r}^{2}$ & 0.9792 & 0.9796 & 0.9861 & 0.9723 & 0.987 & 0.9861 & 0.985 & 0.992 \\
\hline \multicolumn{9}{|c|}{ Dubinin-Raduskevich Isotherm } \\
\hline $\mathrm{q}_{\mathrm{D}}(\mathrm{mg} / \mathrm{g})$ & 71.59 & 82.18 & 94.24 & 109.85 & 120.13 & 126.65 & 105.88 & 116.87 \\
\hline $\mathrm{E}(\mathrm{kJ} / \mathrm{mol})$ & 0.4082 & 0.5 & 0.7454 & 1.291 & 0.845 & 1.000 & 1.118 & 1.118 \\
\hline$r^{2}$ & 0.7423 & 0.6977 & 0.6866 & 0.7217 & 0.7544 & 0.7752 & 0.7442 & 0.7284 \\
\hline
\end{tabular}

A plot of $\log \mathrm{q}_{\mathrm{e}}$ versus $\log \mathrm{C}_{\mathrm{e}}$ gives a linear line with a slope of $1 / \mathrm{n}$ and intercept of $\log \mathrm{k}_{\mathrm{f}}$ and the results are given Table 3 . From the experimental data, $\mathrm{k}_{\mathrm{f}}$ values increased on increasing temperature, implying that the adsorption process is endothermic in nature. Values $\mathrm{n}>1$ represent a favorable adsorption condition. The correlation coefficient values are poor when compared to the Langmuir isotherm model.

The D-R isotherm describes the adsorption on a single uniform pore. DubininRaduskevich isotherm is generally expressed as follows ${ }^{26}$ :

The linear form of $\mathrm{D}-\mathrm{R}$ isotherm equation is represented as:

$$
\begin{aligned}
& \ln q_{e}=\ln q_{D}-B \varepsilon^{2} \\
& \varepsilon=R T \ln \left(1+\frac{1}{C_{e}}\right),
\end{aligned}
$$

where $\mathrm{q}_{\mathrm{D}}$ is the theoretical saturation capacity $(\mathrm{mol} / \mathrm{g}), \mathrm{B}$ is a constant related to the mean free energy of adsorption per mole of the adsorbate $\left(\mathrm{mol}^{2} / \mathrm{J}^{2}\right), \varepsilon$ is the Polanyi potential. The $D-R$ constants $q_{D}$ and $B$ were calculated from the linear plots of $\ln \mathrm{q}_{\mathrm{e}}$ versus $\varepsilon^{2}$ (figure not shown) and the results are given in Table 3 . The constant $\mathrm{B}$ gives an idea about the mean free energy $\mathrm{E}(\mathrm{kJ} / \mathrm{mol})$ of adsorption per molecule of the adsorbate when it is transferred to the surface of the solid from the solution and can be calculated from the following relationship ${ }^{27}$

$$
\mathrm{E}=1 /(2 \mathrm{~B})^{1 / 2}
$$


The adsorption is physisorption when the energy of activation is 5 to $40 \mathrm{~kJ} / \mathrm{mol}$ and chemisorption when the energy of activation is 40 to $800 \mathrm{~kJ} / \mathrm{mol}^{28}$. From the Table 3, it was suggested that the adsorption of DB71 by TPAC and PPC is physisorption in nature. D-R isotherm is not able to describe the experimental data properly because of the poor correlation coefficient.

\section{Thermodynamics of Adsorption}

Thermodynamic parameters provide in-depth information of inherent energetic changes associated with adsorption; therefore, these parameters should be accurately evaluated. Langmuir isotherm equation was applied to calculate the thermodynamic parameters as follows:

$$
\begin{aligned}
\Delta G^{\circ} & =-R T \ln k_{L} \\
\ln \mathrm{k}_{L} & =\frac{\Delta S^{\circ}}{R}-\frac{\Delta H^{\circ}}{R} \frac{1}{T},
\end{aligned}
$$

where $\mathrm{k}_{\mathrm{L}}$ is the Langmuir equilibrium constant, $\Delta H^{\circ}$ and $\Delta S^{\circ}$ are the standard enthalpy and entropy changes of adsorption respectively.

Thermodynamic parameters like $\Delta H^{\circ}, \Delta S^{\circ}$ and $\Delta G^{\circ}$ were determined from the slope and intercept of Van't Hoff's plot of $\ln \mathrm{k}_{\mathrm{L}}$ versus 1/T (figure not shown) and the results are given in Table 4. The $\Delta G^{\circ}$ values indicating that the adsorption of DB71 is spontaneous and thermodynamically favorable. The positive $\Delta H^{\circ}$ values indicate that the adsorptions of DB71 dye onto TPAC and PPC was an endothermic process, which was supported by the increase of adsorption of the dye with increase in temperature. Furthermore, the positive $\Delta S^{\circ}$ indicates that the degrees of freedom increased at the solid - liquid interface during adsorption of the direct dye. Generally, $\Delta G^{\circ}$ for physisorption is between -20 to $0 \mathrm{~kJ} / \mathrm{mol}$ and for chemisorption is between -80 to $-400 \mathrm{~kJ} / \mathrm{mol}^{29}$.

The $\Delta G^{\circ}$ values were calculated from equation (12) and given in Table 4 . This confirms that the adsorption of DB71 onto the given adsorbents (TPAC and PPC) is physisorption.

Table 4. Thermo dynamical parameters from Van't Hoff plots for the adsorption of direct

\begin{tabular}{|c|c|c|c|c|c|c|}
\hline \multirow[b]{2}{*}{ 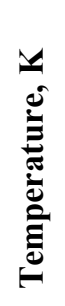 } & \multicolumn{3}{|c|}{ TPAC } & \multicolumn{3}{|c|}{ PPC } \\
\hline & 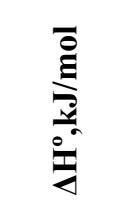 & 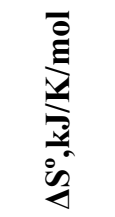 & 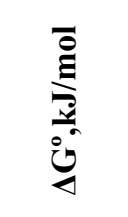 & 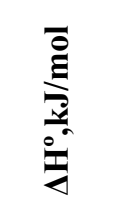 & 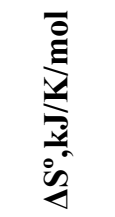 & 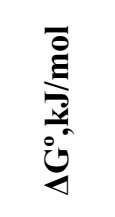 \\
\hline 303 & 76.0223 & \multirow{4}{*}{0.2644} & -4.0909 & 19.424 & \multirow{4}{*}{0.0889} & -7.5127 \\
\hline 308 & 76.0223 & & -5.4129 & 19.424 & & -7.9572 \\
\hline 313 & 76.0223 & & -6.7349 & 19.424 & & -8.4017 \\
\hline 318 & 76.0223 & & -8.0569 & 19.424 & & -8.8462 \\
\hline
\end{tabular}
dye DB 71 onto TPAC and PPC at various temperatures. 


\section{Desorption Studies}

The desorption of dyes by mineral acids and alkaline medium indicates the dyes are adsorbed onto the activated carbon by physisorption. Maximum desorption of DB71 is $31.5 \%$ for TPAC and $42.3 \%$ for PPC at a pH range of 6 to 8 . There is no change in desorption of the direct dye DB71 above the $\mathrm{pH}$ of 8 .

\section{Conclusions}

In this investigation, activated carbon (TPAC) and polymer composite (PPC) were prepared from the wood of Thevetia Peruviana for the adsorption of Direct Blue 71 from its aqueous solution. The amount of DB71 adsorption increased from $31.48 \mathrm{mg} / \mathrm{g}$ to $107.69 \mathrm{mg} / \mathrm{g}$ for TPAC and $48.15 \mathrm{mg} / \mathrm{g}$ to $166.10 \mathrm{mg} / \mathrm{g}$ for PPC with an increase in the initial concentrations from 25 to $100 \mathrm{mg} / \mathrm{L}$. The adsorption of the DB71 increased with increase in temperature indicates that the adsorption is endothermic in nature. Kinetic studies showed that adsorption of DB71 by TPAC and PPC followed pseudo- second order model. The data obtained from adsorption isotherms are well fitted with Langmuir model which suggests the monolayer coverage of the dye on surfaces of TPAC and PPC. The negative $\Delta G^{\circ}$ values obtained from Van't Hoff plots confirm that the adsorption of DB71 by these adsorbents is spontaneous in nature. The Positive $\Delta H^{\circ}$ values suggest that the adsorptions of the direct dye on TPAC and PPC are endothermic in nature. From the kinetic and thermodynamic analyses, it was suggested that the polymer composite PPC is suitable for the removal of DB71 compared to the activated carbon TPAC.

\section{Acknowledgments}

The second and third authors gratefully acknowledge the financial support given by the University Grants Commission (UGC), New Delhi under the Major research project scheme to carry out this research project.

\section{References}

1. O’Neill C, Hawkes F R, Lourenco N D, Pinheiro H M and Delee W, J Chem Technol Biotechnol., 1999, 74, 1009-1018.

2. Willmott N, Guthir J, Nelson G, J. Soc. Dye color.,1998, 114 ,38-41.

3. Kaushik C P, Tuteja R, Kaushik N and Sharma J K, Chem. Eng. J., 2009,115, 234-240.

4. Bayramoglu G and Arica M Y, J. Hazard. Mater., 2007, 143, 135-143.

5. Inbaraj B S, Selvarani K and Sulochana N, J.Sci.Ind.Res., 2002, 61, 971-978.

6. Fu Y, Viraraghavan T, Water SA, 2003, 29, 465-472.

7. Ghosh D, Bhattacharyya K G, Appl. Clay Sci., 2002, 20, 295-300.

8. Namasivayam C, Kumar D M and Selvi K, Bio- mass Bioenergy, 2001, 21,477-483.

9. Rahman I A, Saad B, Malays.J.Chem., 2003, 5, 8-14.

10. Khatri S D and Singh M K,Water, Air \& Soil Pollution.2000, 120 , 283-294.

11. Gurses A, Karaca S, Dogar C, Bayrak R, Acikyildiz M and Yalcin M, J. Colloid Interface Sci., 004, 269, 310-314.

12. Vasanth K and Kumar A, Biochem Eng J., 2005, 27 , 83-93.

13. Reza Ansari and Zahra Mosayebzadeh, Iran.Polym.J., 2010, 19 ,541-551.

14. ISI, Activated Carbon, Bureau of Indian Standards, New Delhi, 1989, IS 877.

15. American Society for Testing Materials (ASTM), 1980, D4607-94.

16. Ansari R, Acta Chim Slov., 2006, 53 , 88-94.

17. Ansari R and Fahim N K, React Funct Polym., 2007, 67 , 374-367. 
18. Ahsan Habib, Zahidul Hasan, Shajedur Rahman A S M and Shafiqul Aslam A M, Pak.J.Anal. \&Envir. Chem., 2006, 7 , 112-115.

19. Yusra Safa and Haq Nawaz Bhatti, African.J. Biotech., 2011, 10 , 3128-3142.

20. Chao-Yin Kuo, Wu C H and Wu J Y, J.Colloid Interface Sci.,2008, 327,308-315.

21. Jai Kumar V, Sathish Kumar K and Gnana Prakash D, Int.J.App.Sci\& Engg., 2009, 7, 115- 125.

22. Lagergren S, Kung Sven Veten Hand., 1898, 24,1 -39.

23. Sudipta Chattergee, Due. S. Lee, Min.W.Lee and Seung.H.Woo, Bio Res.Tech., 2009, 100, 2803-2809.

24. Nwabanne J T and Mordi M I, African .J.Bio Tech. 8(2009) 1555-1559.

25. Ahmad A A, Hameed B H and Aziz N, J. Hazard. Mater., 2007,141, 70-76.

26. Dubinin M M, Chem. Rev., 1960, 60, 235.

27. Ozcan A S, Erdem B and Ozcan A, Colloids Surfaces A: Physicochem. Eng Aspect. 2005, $266,73$.

28. Arh-Hwang Chen and Shin-Ming Chen, J.Hazard.Mater., 2009, 172, 1111-1121.

29. Haycock M J and Parfitt G D, Chemistry of Interfaces, Ellis Horwood Ltd.Chichester, 1981. 




International Journal of

Medicinal Chemistry

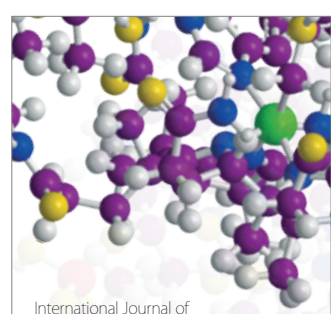

Carbohydrate Chemistry



The Scientific World Journal
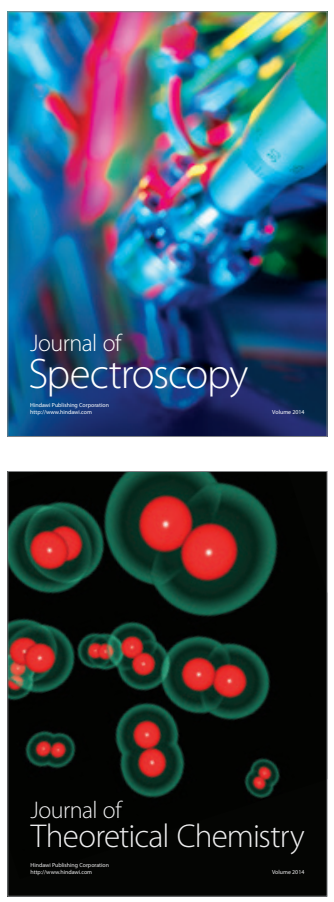


Submit your manuscripts at

http://www.hindawi.com
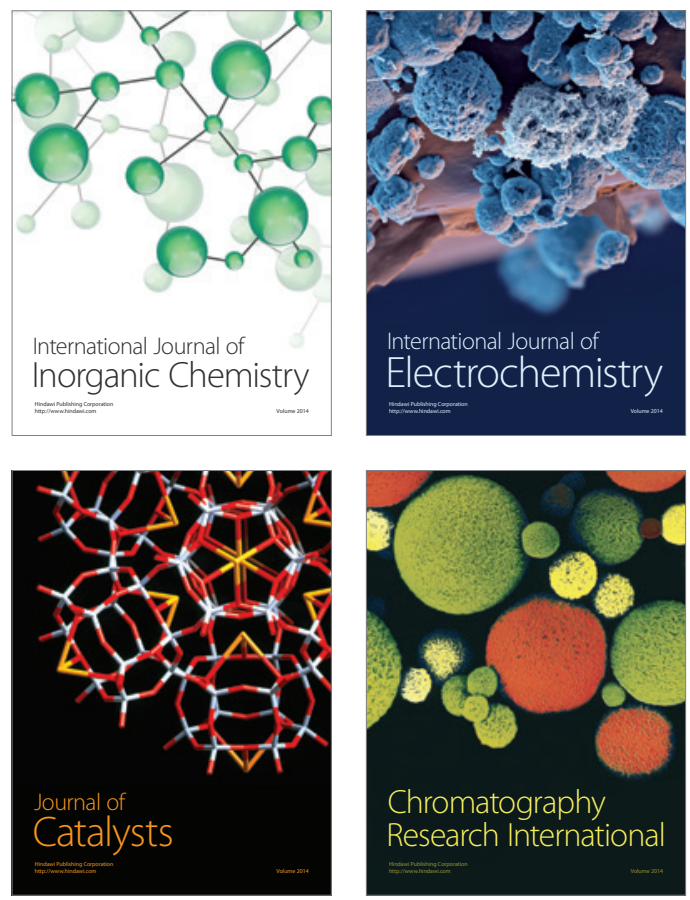
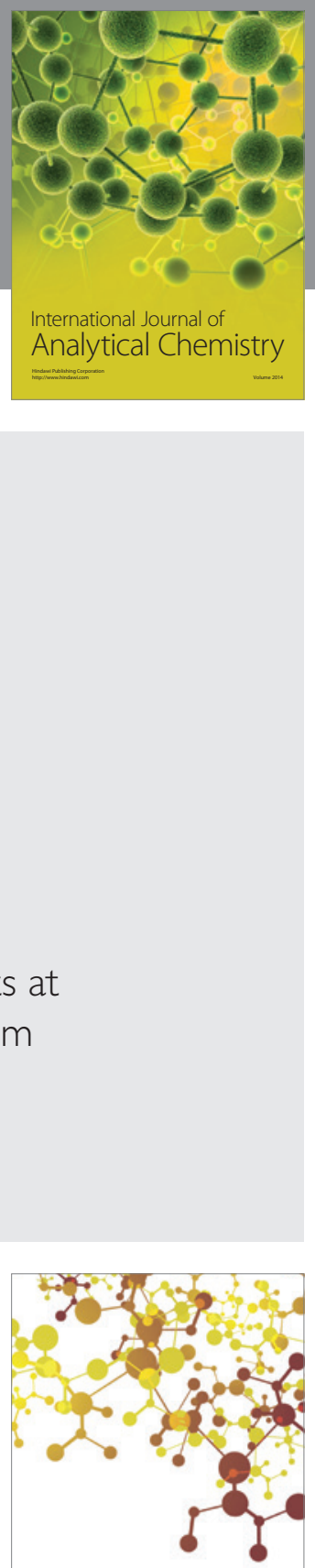

Journal of

Applied Chemistry
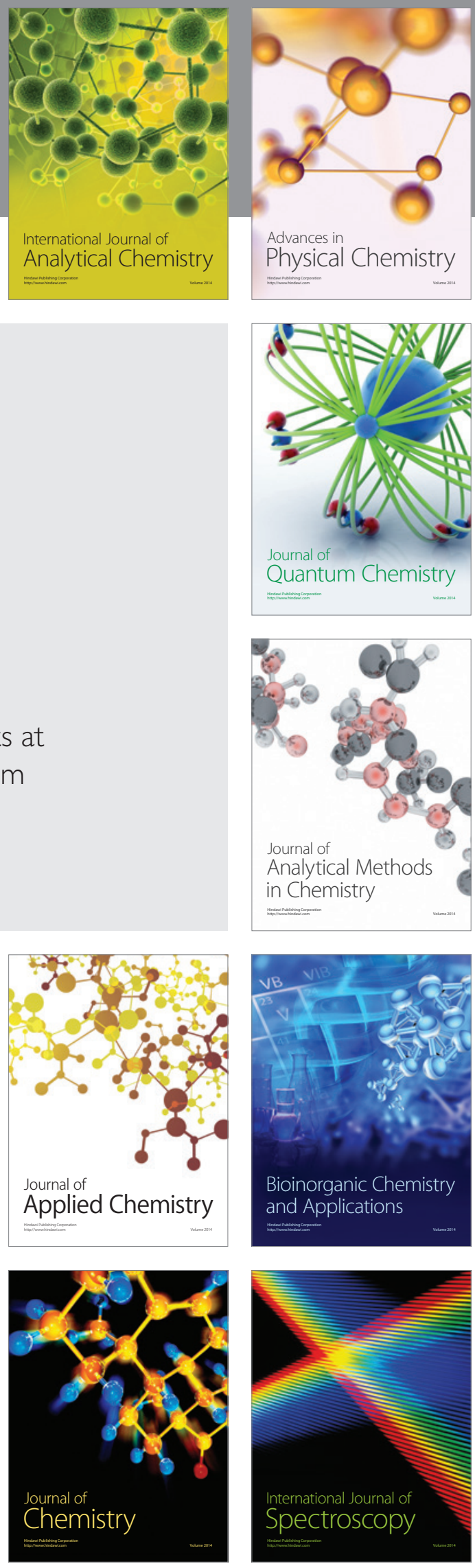